\title{
N90-28273
}

\section{RELATIONSHIP BETWEEN THE LONGWAVE CLOUD RADIATIVE FORCING AT THE SURFACE AND THE TOP OF THE ATMOSPHERE}

\author{
Harshvardhan
}

\author{
Department of Earth and Atmospheric Sciences \\ Purdue University, West Lafayette, IN 47907
}

In order to achieve global coverage, any surface radiation climatology has to be based on satellite observations. In the last decade several schemes have been devised to obtain the surface solar insolation from top of the atmosphere reflected solar radiation (Tarpley, 1979; Gautier et al., 1980). More recently, attempts have been made to infer the components of longwave radiation at the surface from satellite sounder data using a radiative transfer model (Schmetz et al., 1986; Frouin et al., 1988; Gupta, 1989). In addition to the radiative transfer scheme, these methods require assumptions about the effective emitting temperature of cloud tops and bases. The one common theme in these methods is an assumption regarding the vertical extent of the cloudiness detected in the upwelling radiation. Once the top is placed using a coincident sounding, the position of the base is estimated by various methods, the simplest being an assumption of constant cloud depth. During the day, the reflected solar radiation has also been used to estimate the geometric depth of the cloud layer (Frouin et al., 1988), a complex procedure that involves assumptions regarding cloud microphysics and morphology.

Modeling studies have shown that although there are strong correlations between the solar upwelling radiative flux and surface flux, this is not true of the longwave (Ramanathan, 1986). However, if the clear sky component is considered separately such that the cloud longwave forcing at the top and at the surface are compared, a slightly different picture emerges. Figure 1 shows the monthly mean simulated longwave radiation at the top of the atmosphere and at the surface from a general circulation model (Harshvardhan et al., 1989). Each point represents a $4^{\circ}$ latitude $\times 5^{\circ}$ longitude grid. During the simulation, in addition to the hourly radiative fields generated as part of the model integration, a clear sky computation was also made every hour. The difference, which is the cloud forcing, was thus obtained at the top of the atmosphere and the surface. Figure 2 shows the longwave cloud radiative forcing at these levels for all the grid points in the model. This figure contains information on the relationship between emission from the cloud tops and bases in the model. For example, a subset of the simulated data for two latitude bands is shown in Figures 3 and 4 . Figure 3 is for a region of high convective clouds and the cloud radiative forcing at the top is very large when cloudiness occurs where as the surface longwave fluxes are not affected much. Figure 4 is for a region of low clouds such that the cloud top emission is not too different from the surface emission but the downward longwave radiation is altered quite drastically in the presence of clouds.

During the FIRE Cirrus IFO, surface radiation measurements were made at several sites and co-incident satellite overpass data was also collected (LeCroy et al., 1989). It may be possible to extract the longwave cloud radiative forcing at the top and the surface from these data. If relationships, such as shown in Figures 3 and 4 are verifiable by observations, this information can be useful for the extraction of the surface longwave radiation from satellite data. The radiative transfer schemes used to convert upwelling spectral radiances into a downwelling longwave radiation can provide the clear sky component. The cloud radiative forcing at the top of the atmosphere can then modify the surface fluxes according to relationships shown in Figures 3 and 4 . It should be noted that this procedure may be considered only for temporal averages and not for instantaneous deductions of surface fluxes. This would be most useful in compiling monthly mean regional climatologies of the surface longwave fluxes. 


\section{$\underline{\text { References }}$}

Frouin, R., C. Gautier and J.-J. Morcrette, 1988: Downward longwave irradiance at the ocean surface from satellite data. J. Geophys. Res., 93, 597-619.

Gautier, C., G. Diak and S. Masse, 1980: A simple physical model to estimate incident solar radiation at the surface from GOES satellite data. J. Appl. Meteor., 19, 1005-1012.

Gupta, S.K., 1989: A parameterization for longwave surface radiation from sun-synchronous satellite data. J. Climate, 2, 305-320.

Harshvardhan, D.A. Randall, T.G. Corsetti and D.A. Dazlich, 1989: Earth radiation budget and cloudiness simulations with a general circulation model. J. Atmos. Sci., 46, (in press).

LeCroy, S.R., C.H. Whitlock, L.R. Poole, J.M. Alvarez, D.A. Robinson, D.O'C. Starr and S.K. Cox, 1989: Surface radiation observations of cirrus cloud properties during the Wisconsin FIRE/SRB experiment. Proceedings of IRS 1988, A. Deepak Publishing, Hampton, VA.

Ramanathan, V., 1986: Scientific uses of surface radiation budget data for climate studies. NASA RP $1169,59-86$.

Schmetz, P., J. Schmetz and E. Raschke, 1986: Estimation of daytime downward longwave radiation at the surface from satellite and grid point data. Theor. Appl. Climatol., 37, 136-149.

Tarpley, J.D., 1979: Estimating incident solar radiation at the surface from geostationary satellite data. J. Appl. Meteor., 18, 1172-1181. 


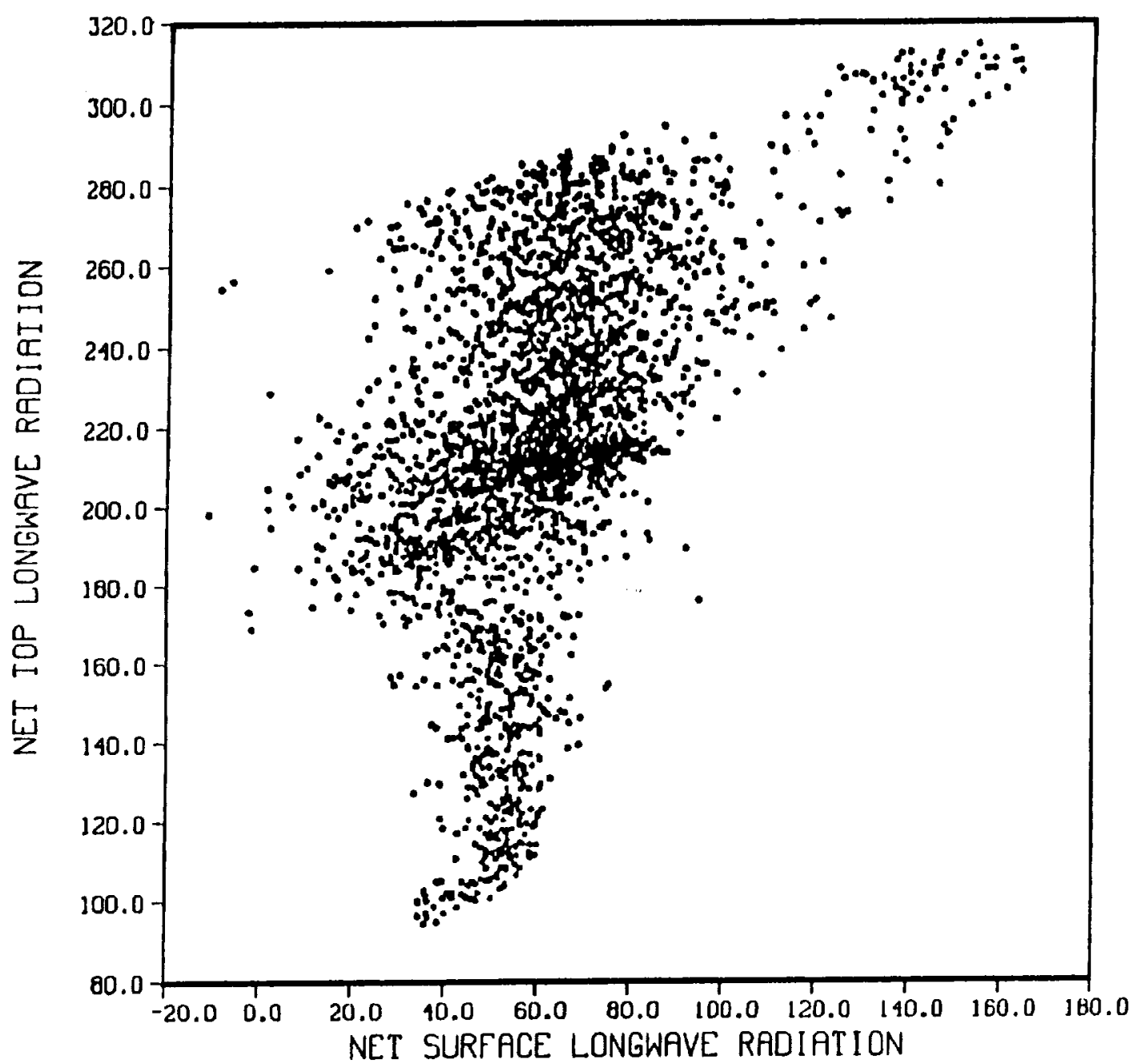

Figure 1. Monthly mean (July) outgoing longwave radiation at the top of the atmosphere plotted versus the net surface longwave radiation for each $4^{\circ}$ lat $\times 5^{\circ}$ long grid point of a general circulation model. 


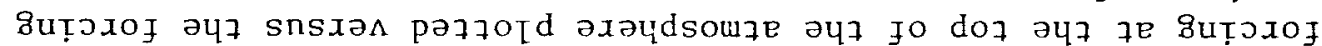

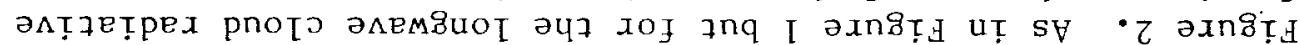

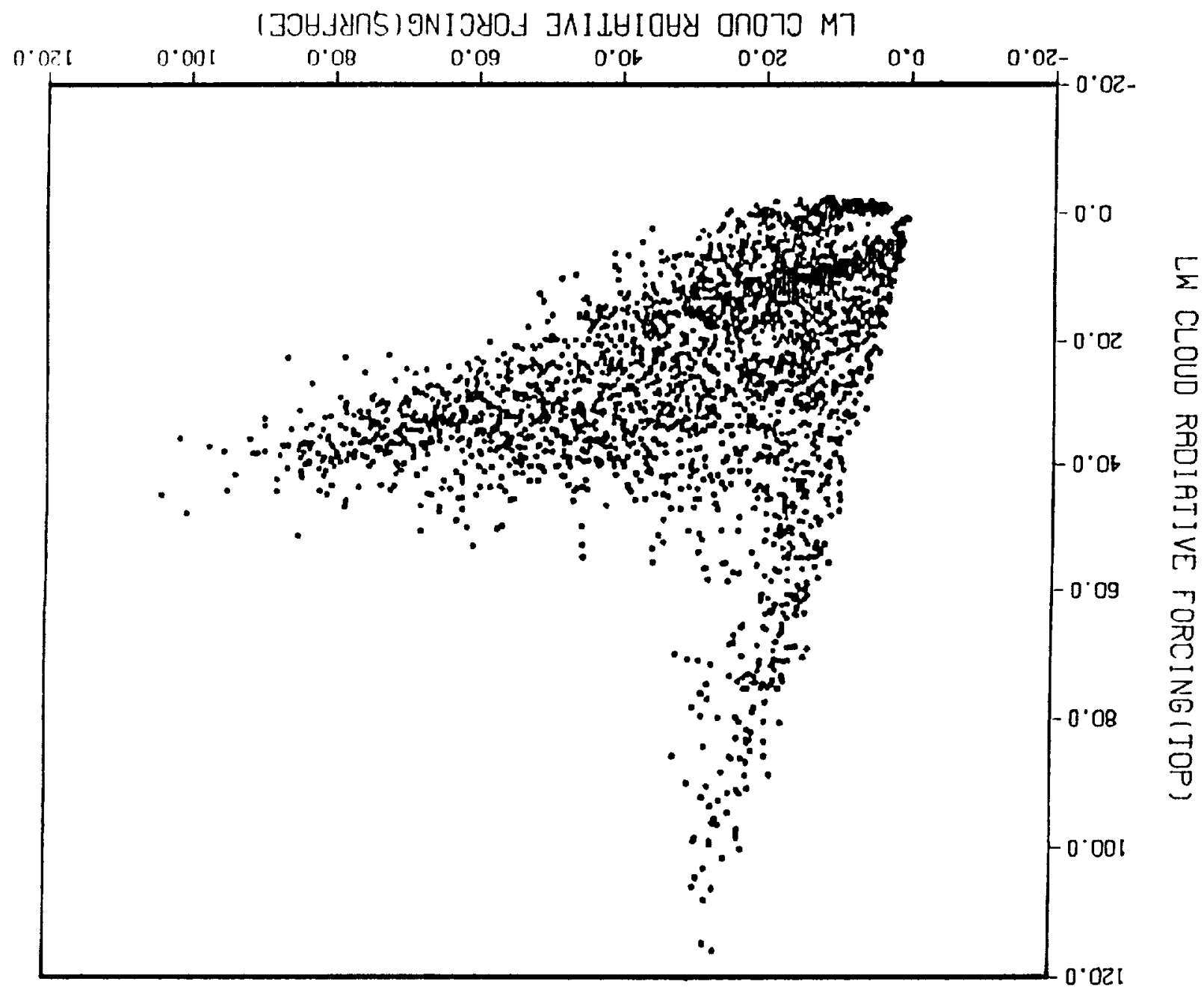




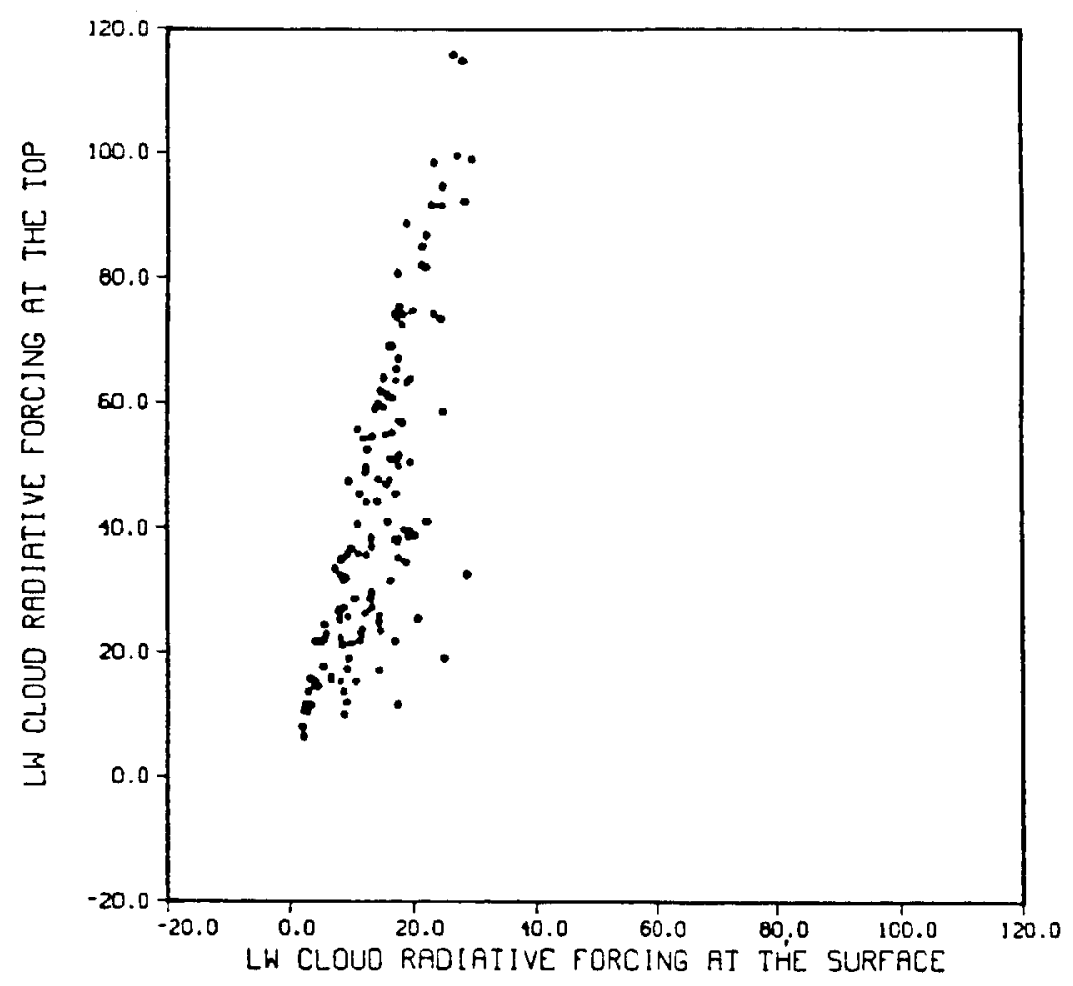

Figure 3. As in Figure 2 but for the grid points in a latitude band from $10 \mathrm{~N}$ to $14 \mathrm{~N}$.

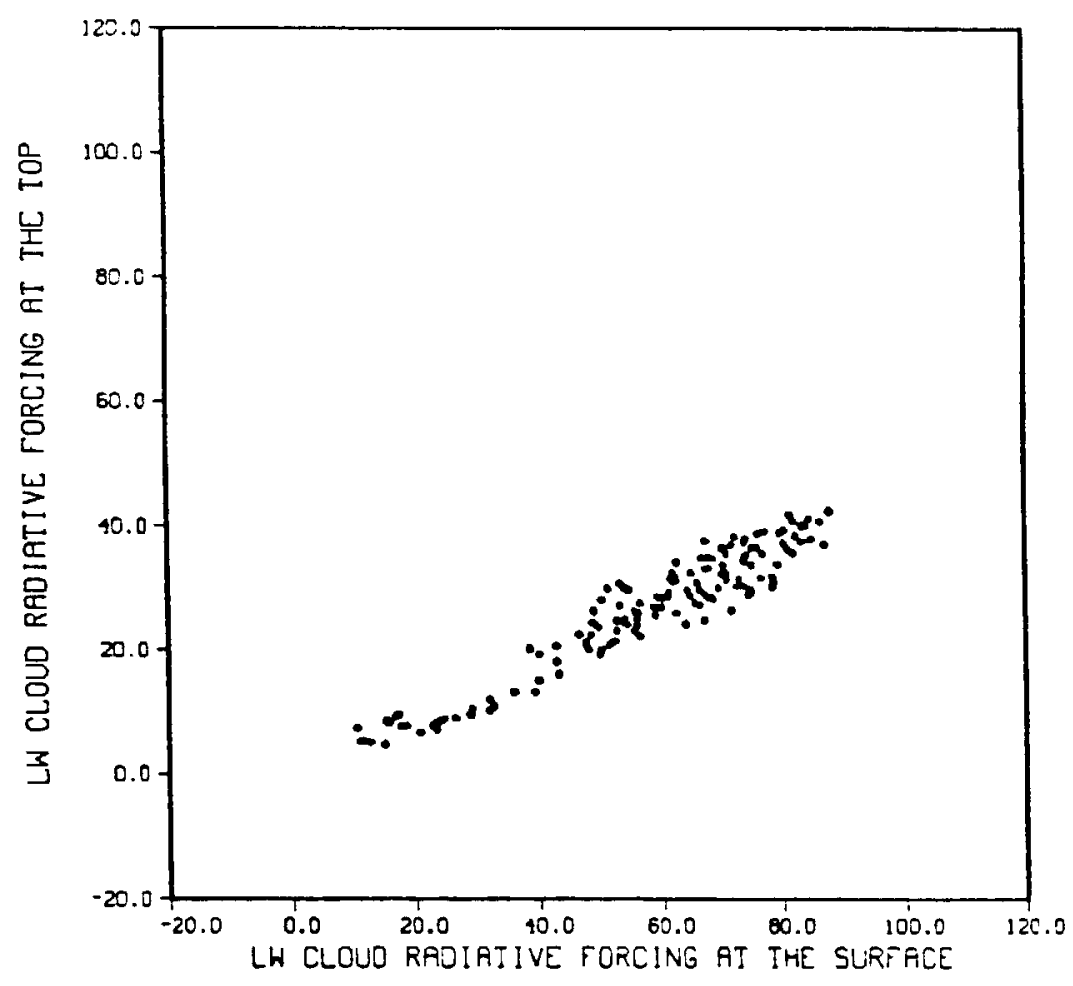

Figure 4. As in Figure 2 but for the grid points in a latitude band from $58 \mathrm{~S}$ to $62 \mathrm{~S}$. 


$$
1
$$

